\title{
REFERENCES
}

Ball, S., Collins, F. D., Dalvi, P. D. \& Morton, R. A. (1949). Biochem. J. 45, 304.

Ball, S., Collins, F. D., Morton, R. A. \& Stubbs, A. L. (1948). Nature, Lond., 161, 424.

Ball, S., Goodwin, T. W. \& Morton, R. A. (1948). Biochem. J. 42, 516.

Bliss, A. F. (1946). J. gen. Physiol. 29, 249.

Bliss, A. F. (1948). J. biol. Chem. 176, 563.

Bliss, A. F. (1949). Biol. Bull. 97, 50.

Collins, F. D. \& Morton, R. A. (1950). Biochem. J. 47, 3.

Lythgoe, R. J. (1937). J. Physiol. 89, 331.
Lythgoe, R. J. \& Quilliam, J. P. (1938). J. Physiol. 94, 399.

Morton, R. A. \& Goodwin, T. W. (1944). Nature, Lond., 153, 405.

Morton, R. A. \& Stubbs, A. L. (1946). Analyst, 71, 348.

Oster, G. (1948). Chem. Rev. 43, 319.

Schneider, E. E., Goodeve, C. F. \& Lythgoe, R. J. (1939). Proc. roy. Soc. A, 170, 102.

Wald, G. (1934). J. gen. Physiol. 18, 905.

Wald, G. (1935). J. gen. Physiol. 19, 351.

Wald, G. (1936). J. gen. Physiol. 19, 781.

Wald, G. (1949). J. gen. Physiol. 32, 367.

\section{Studies in Rhodopsin}

\section{RHODOPSIN AND TRANSIENT ORANGE}

\author{
By F. D. COLLINS and R. A. MORTON \\ Department of Biochemistry, University of Liverpool
}

(Received 27 October 1949)

The existence of transient orange was first established by Lythgoe \& Quilliam (1938), who showed that if a rhodopsin solution was irradiated at a temperature near $0^{\circ}$, a comparatively stable orange colour resulted, but if the solution was warmed to room temperature it became much paler (colourless at alkaline $\mathrm{pH}$ ). The unstable orange substance showed $\lambda_{\max }$ at about $470 \mathrm{~m} \mu$. and, on warming, this 'transient orange' changed to 'indicator yellow'. Further work (Broda \& Goodeve, 1941) showed that at $-70^{\circ}$ transient orange was stable and insensitive to light. Lythgoe accordingly formulated the photodecomposition of rhodopsin as follows :

$$
\text { rhodopsin }+h_{\nu} \rightarrow \text { transient orange, }
$$

followed by a thermal process

$$
\text { transient orange } \rightarrow \text { indicator yellow. }
$$

Lythgoe (1940), in a review of dark adaptation, referred to a possible regeneration of rhodopsin from transient orange, but he did not live to develop his ideas. He also suggested that the regenerated rhodopsin had a maximum differing a little from that of untreated rhodopsin, but did not indicate in which direction the shift occurred.

Chase \& Smith (1939) exposed rhodopsin solutions to light of various wavelengths, and with blue light obtained $15 \%$ regeneration. The regenerated rhodopsin showed $\lambda_{\max }$. slightly less than $500 \mathrm{~m} \mu$., but they were not quite certain that the difference was outside experimental error.

The whole problem seems ripe for reinvestigation.

\section{EXPERIMENTAL}

\section{Solutions}

Sucrose. $45 \mathrm{~g} . / 100 \mathrm{ml}$. water.

Alum. $\left(\mathrm{K}_{2} \mathrm{SO}_{4} \cdot \mathrm{Al}_{2}\left(\mathrm{SO}_{4}\right)_{3} \cdot 24 \mathrm{H}_{2} \mathrm{O}\right): 4 \mathrm{~g}$. $/ 100 \mathrm{ml}$. water.

Digitonin. A $1 \%(\mathrm{w} / \mathrm{v})$ solution in water was prepared just before use by boiling the requisite amounts of digitonin and water until all the digitonin had dissolved, and then cooling.

Buffer solutions. McIlvaine's standard buffer solutions were used (Clark, 1928) for the $\mathrm{pH}$ range 6-8 and for $\mathrm{pH} 9 \cdot 2$ a solution of borax $\left(\mathrm{Na}_{2} \mathrm{~B}_{4} \mathrm{O}_{7} .10 \mathrm{H}_{2} \mathrm{O}\right), 19 \mathrm{~g}$./l., was used.

Light petroleum. B.p. $40-60^{\circ}$.

Solid carbon dioxide was used to freeze the solutions, generally in an ethanol bath, which was cooled by the refrigerant to $-70^{\circ}$.

The absorption spectra were determined by means of the Beckman quartz photoelectric spectrophotometer using a $1 \mathrm{~cm}$. cell.

\section{Preparation of rhodopsin solutions}

The procedure was that described by Collins \& Morton $(1950 a)$ and will only be briefly referred to here. All work was done in red light unless otherwise stated.

The retinas from frogs (Rana temporaria), rats or bullocks (eyes obtained from an abattoir soon after killing) were shaken with sucrose solution and centrifuged. The supernatant liquid, containing a suspension of rods, was decanted. The suspension was then diluted with water and the rods thrown down by recentrifuging. The rods were then hardened in alum for $2 \mathrm{hr}$. The alum solution was removed by centrifuging and the rod preparation was then extracted with digitonin solution for $1 \mathrm{hr}$. The digitonin extract, after centrifuging to remove retinal debris, was then mixed with 
an appropriate buffer solution, recentrifuged to ensure optical clarity and was then ready for use.

This procedure was occasionally varied; sometimes the treatment with alum was omitted, or the whole retina was hardened in alum and subsequently extracted with digitonin solution.

\section{The 'regeneration' of rhodopsin}

The solution of rhodopsin, obtained as described above, was transferred to a squat $30 \mathrm{ml}$. beaker. The $2-3 \mathrm{ml}$. of solution formed a thin layer and were frozen by lowering the base of the beaker into ethanol cooled to $-70^{\circ}$. After the solution had been kept frozen for 5-6 min. it was illuminated for about $30 \mathrm{~min}$. In the earlier experiments a $100 \mathrm{~W}$. lamp was suspended $30 \mathrm{~cm}$. above the bath containing the frozen rhodopsin solution. In the later experiments a 500 c.p. 'Point-o-lite' lamp was used with a reflector above it and a filter beneath. The filter consisted of a solution of $\mathrm{CuCl}_{2}$ (approx. $10 \% \mathrm{w} / \mathrm{v}$ ) which transmitted freely light of wavelengths between 400 and $550 \mathrm{~m} \mu$. and effectively cut off infrared radiation.

The freshly frozen rhodopsin solution was pink in colour, but on exposure to light changed to orange. The colour always seemed rather pale, probably because of scattering by the ice crystals. The frozen solution was rotated at intervals to ensure uniform illumination and was also held upside down to make sure that all the rhodopsin was reached by the light.

After irradiation the solution was thawed and kept at room temperature, in complete darkness for $1 \mathrm{hr}$. The absorption spectrum was then determined; the cells being filled in the dark room (red light) and carried to the Beckman spectrophotometer under a black cloth and placed in position. The instrument has a light-proof compartment for the cells and the intensity of the monochromatic light passing through the cells during the determinations is very small.

The process of irradiating at $-70^{\circ}$ and then measuring the absorption spectrum at room temperature was repeated several times on the same solution. In one case the absorption spectrum was only measured at some of the stages. For every preparation the final irradiation was carried out at room temperature.

Solutions of $\mathrm{pH}$ values $6 \cdot 7, \mathbf{7 \cdot 4}$ and $\mathbf{7 \cdot 6}$ were tried, but the

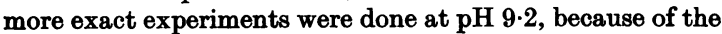
convenient fact that alkaline indicator yellow has little or no absorption at $500 \mathrm{~m} \mu$.

Two experiments were carried out in a different way; in each case $10 \mathrm{ml}$. of an ox-rhodopsin solution (approx. $\mathrm{pH}$ 9) was used, and a $2 \mathrm{ml}$. sample was taken and its absorption curve measured before and after complete bleaching at room temperature. The remaining $8 \mathrm{ml}$. were then frozen to $-70^{\circ}$ and irradiated. After standing at room temperature for $1 \mathrm{hr}$. in the dark another $2 \mathrm{ml}$. sample was taken and its absorption measured; it was then fully bleached at room temperature and the absorption measured again. The remaining $6 \mathrm{ml}$. were again frozen, irradiated at low temperature and the sequence of operations repeated.

\section{RESULTS}

Table 1 gives the numerical results obtained in the repeated 'regeneration' of rhodopsin, and displays the main findings. Figs. 1 and 2 illustrate a point not shown in Table 1, namely that the regenerated curves apparently possess an isosbestic point through which the original curve does not pass (Fig. 1), and in the case of rat rhodopsin there appears to be superimposed and changing irrelevant absorption. This makes it necessary to tabulate the findings on selective absorption over a fairly wide range of wavelengths and to note how a constant instrumental limitation. will affect the evidence (which will be discussed in detail) for $50 \%$ regeneration.

\section{DISCUSSION}

A relation between absorption curves for repeated 'regeneration' of visual pigment can be obtained as follows.

Let $\epsilon=$ molecular extinction coefficient of rhodopsin at any wavelength $\lambda$ in the near ultraviolet or visible regions. Also, let $c$ (g. mol./l.) = the initial concentration of the rhodopsin, and after successive regenerations let the concentration of rhodopsin be $r_{1} c, r_{1} r_{2} c, r_{1} r_{2} r_{3} c \ldots, r_{1} r_{2} \ldots r_{n} c$.

Let $a$ be the extinction of indicator yellow (at wavelength $\lambda$ ) due to the completely bleached rhodopsin expressed as a fraction of $\epsilon$ (rhodopsin).

Finally, let the irrelevant absorption at $\lambda$ be $d$ and the length of the cell be $1 \mathrm{~cm}$.

Therefore the initial extinction

$$
=E_{0}=c \epsilon+d \text {, }
$$

after one 'regeneration'

$$
=E_{1}=r_{1} c \epsilon+\left(1-r_{1}\right) a c \epsilon+d,
$$

after $n$ 'regenerations'

$$
=E_{n}=r_{1} r_{2} \ldots r_{n} c \epsilon+\left(1-r_{1} r_{2} \ldots r_{n}\right) a c \epsilon+d,
$$

after complete bleaching

$$
=E_{f}=a c \epsilon+d \text {. }
$$

Subtracting the final value from each of the other values we obtain the series:

$$
\begin{aligned}
& 0 \quad c \epsilon(1-a) \\
& 1 r_{1} c \epsilon(1-a) \\
& 2 \quad r_{1} r_{2} c \epsilon(1-a) \\
& \begin{array}{ccc}
\vdots & \vdots & \vdots \\
n & r_{1} r_{2} \ldots r_{n} c \epsilon(1-a) .
\end{array}
\end{aligned}
$$

Hence the ratio of any two successive differences is $r_{n}$, and this is independent of $c, \epsilon$ or $a$ provided $d$ is constant. If $\epsilon$ for the 'regenerated' rhodopsin is different from that of the original rhodopsin a factor for this will be included in $r_{n}$. The observed value of $r_{n}$ will differ from its true value if $d$ (the irrelevant absorption) is not constant during the experiment.

The error in the experimental value of

$$
r_{n}\left(=\frac{E_{n-1}-E_{f}}{E_{n}-E_{f}}\right)
$$

can be calculated as follows: if $\delta$ is the error (fiducial limits) in $E_{n}$, then the error in $\left(E_{n-1}-E_{f}\right)$ will be $\sqrt{ }\left(\delta^{2}+\delta^{2}\right)=\delta \sqrt{2}$

The error in the quotient $\frac{E_{n-1}-E_{f}}{E_{n}-E_{f}}$ will be

$$
\frac{E_{n-1}-E_{f}}{E_{n}-E_{f}}\left[\left(\frac{\delta \sqrt{ } 2}{E_{n}-E_{f}}\right)^{2}+\left(\frac{\delta \sqrt{ } 2}{E_{n-1}-E_{f}}\right)^{2}\right]^{\frac{1}{2}},
$$




\section{Table 1. Details of experiments on the regeneration of rhodopsin}

(Solutions prepared from alum-hardened rods, $E_{500 \mathrm{~m} \mu .}$ measured initially and $\lambda_{\max }$ and $E_{\max }$ measured after irradiation at $-70^{\circ}$, followed by $1 \mathrm{hr}$. at room temperature (lst step); irradiation and regeneration repeated (2nd step) et seq.)

\begin{tabular}{|c|c|c|c|c|c|c|c|c|c|}
\hline Species & & & Frog & & & Rat & & $\mathrm{Ox}$ & \\
\hline Number of retinas & 9 & 12 & 12 & 20 & 30 & 60 & 24 & 24 & \\
\hline Vol. of rhodopsin solution (ml.) & $2 \cdot 5$ & $2 \cdot 5$ & $\mathbf{2 \cdot 5}$ & $\mathbf{2 \cdot 5}$ & $\mathbf{2 \cdot 5}$ & $2 \cdot 5$ & $10^{*}$ & $10^{*}$ & - \\
\hline $\mathbf{p H}$ & $7 \cdot 6$ & $6 \cdot 7$ & $8 \cdot 0$ & $9 \cdot 2$ & $9 \cdot 2$ & $9 \cdot 2$ & $8 \cdot 80 \dagger$ & $9 \cdot 2$ & - \\
\hline $\begin{array}{l}\text { Irrelevant absorption: } \\
\text { Initial } E_{700 \mathrm{~m} \mu} \text {. } \\
\text { Final } E_{700 \mathrm{~m} \mu} .\end{array}$ & $\begin{array}{r}-0 \cdot 002 \\
0 \cdot 007\end{array}$ & $\begin{array}{l}0 \cdot 013 \\
0 \cdot 031\end{array}$ & $\begin{array}{l}0 \cdot 017 \\
0 \cdot 068\end{array}$ & $\begin{array}{l}0 \cdot 003 \\
0 \cdot 011\end{array}$ & $\begin{array}{l}0.003 \\
0.008\end{array}$ & $\begin{array}{l}0 \cdot 003 \\
0 \cdot 006\end{array}$ & $\begin{array}{l}0 \cdot 083 \\
0 \cdot 069\end{array}$ & $\begin{array}{l}0 \cdot 014 \\
0 \cdot 006\end{array}$ & After final bleaching \\
\hline Final: $\begin{aligned} & E_{500 \mathrm{~m} \mu} . \\
& E_{\mathrm{4} 90 \mathrm{~m} \mu .}\end{aligned}$ & $\begin{array}{l}0.016 \\
0.017\end{array}$ & $\begin{array}{l}0 \cdot 065 \\
0 \cdot 071\end{array}$ & $\begin{array}{l}0 \cdot 108 \\
0 \cdot 116\end{array}$ & $\begin{array}{l}0 \cdot 027 \\
0 \cdot 028\end{array}$ & $\begin{array}{l}0 \cdot 023 \\
0 \cdot 025\end{array}$ & $\begin{array}{l}0.022 \\
0.026\end{array}$ & $\begin{array}{l}\text { N.M. } \\
\text { N.M. }\end{array}$ & $\begin{array}{l}\text { N.M. } \\
\text { N.M. }\end{array}$ & 二 \\
\hline Initial $E_{500 \mathrm{~m} \mu .}-$ final $E_{500 \mathrm{~m} \mu}$ & $0 \cdot 067$ & $0 \cdot 158$ & $0 \cdot 134$ & $0 \cdot 305$ & $0 \cdot 293$ & $0 \cdot 343$ & $0 \cdot 468$ & $0 \cdot 789$ & $\begin{array}{l}\text { This measures initial } \\
\text { rhodopsin }\end{array}$ \\
\hline $\begin{array}{l}E_{490 \mathrm{~m} \mu .}^{\prime} \text { after first regeneration - } \\
\text { final } E_{490 \mathrm{~m} \mu .}\end{array}$ & 0.034 & 0.085 & 0.091 & N.M. & $0 \cdot 158$ & $0 \cdot 156$ & $0 \cdot 263$ & $0 \cdot 412$ & $\begin{array}{l}\text { This measures initial } \\
\text { regeneration of } i s o- \\
\text { rhodopsin }\end{array}$ \\
\hline$E_{490 \mathrm{~m} \mu .}^{\prime \prime}-$ final $E_{490 \mathrm{~m} \mu .}$ & N.M. & $0 \cdot 046$ & $0 \cdot 056$ & N.M. & $0 \cdot 082$ & 0.071 & $0 \cdot 145$ & $0 \cdot 240$ & Second regeneration \\
\hline$E_{490 \mathrm{~m} \mu}^{\prime \prime \prime}$ - final $E_{490 \mathrm{~m} \mu}$ & N.M. & 0.031 & $0 \cdot 034$ & $0 \cdot 045$ & $0 \cdot 043$ & 0.030 & N.M. & N.M. & Third regeneration \\
\hline$E_{490 \mathrm{~m} \mu .}^{\prime \prime \prime}-$ final $E_{490 \mathrm{~m} \mu}$ & N.M. & N.M. & N.M. & $0 \cdot 026$ & $0 \cdot 030$ & 0.016 & N.M. & N.M. & Fourth regeneration \\
\hline$\lambda_{\max } \mathrm{m} \mu$. rhodopsin & $\begin{array}{l}\text { Approx } \\
500\end{array}$ & .500 & $\begin{array}{r}500- \\
505\end{array}$ & 502 & 503 & 497 & 500 & 500 & - \\
\hline $\begin{array}{l}\lambda_{\max .} m \mu . \text { isorhodopsin } \\
\text { (First regeneration) }\end{array}$ & $\begin{array}{l}\text { Approx } \\
\mathbf{4 9 5}\end{array}$ & $\begin{array}{r}495- \\
500\end{array}$ & $\begin{array}{r}495- \\
500\end{array}$ & $\begin{array}{r}495- \\
500\end{array}$ & 493 & 487 & 488 & 488 & - \\
\hline
\end{tabular}

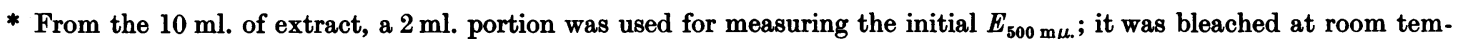
perature and $E_{500 \mathrm{~m} \mu}$. remeasured. The remaining $8 \mathrm{ml}$. were irradiated at $-70^{\circ}$ and brought to room temperature in the dark and the absorption measured on a $2 \mathrm{ml}$. portion before and after complete bleaching at room temperature. The remaining $6 \mathrm{ml}$. was treated similarly, then $4 \mathrm{ml}$.

$\dagger$ pH meter; all other values nominal (buffer solutions).

N.M. means not measured.

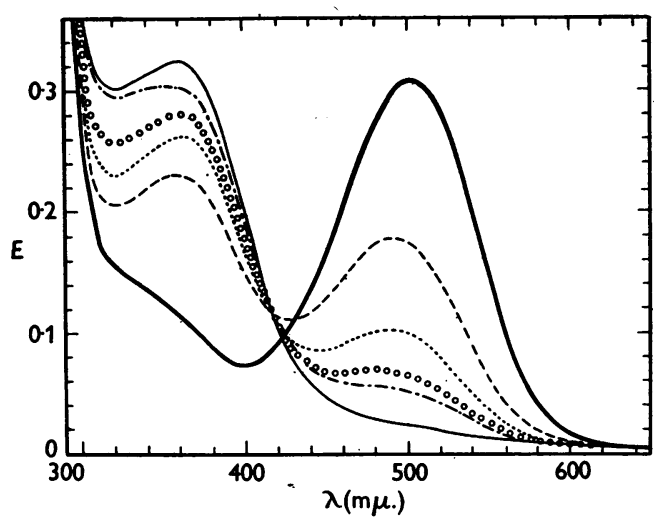

Fig. 1 .

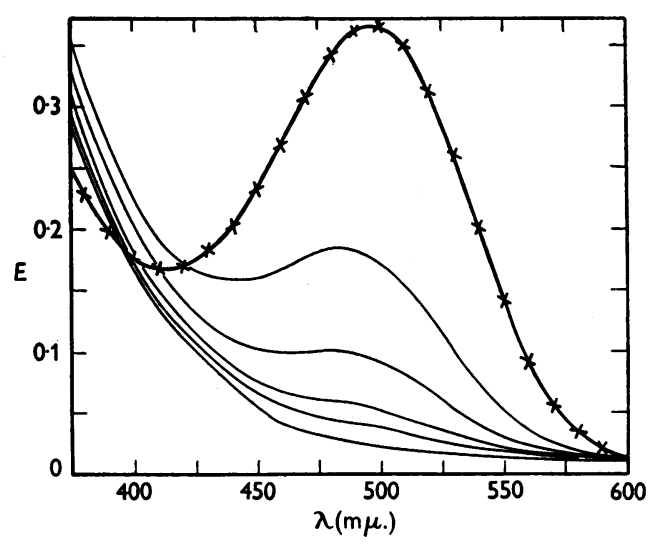

Fig. 2.

Fig. 1. Heavy curve represents fresh unbleached frog rhodopsin solution. This solution was then 'irradiated' at $-70^{\circ}$ and allowed to reach equilibrium in the dark at room temperature (- - -). The succeeding curves show the effect of repeating this process three times. The final curve (-light) was obtained after complete bleaching at room temperature. Note that the $\lambda_{\max }$. for rhodopsin differs from that for the regenerated product and that the initial curve does not pass through the approximately isosbestic point.

Fig. 2. Regeneration of rat rhodopsin (cf. Fig. 1). The displacements at shorter wavelengths seem to be due to an increase in irrelevant absorption. Note the displacement of $\lambda_{\max }$. 
which is the root square mean of the coefficients of variation. This expression is simplified to

$$
\text { or } \begin{aligned}
\frac{\delta \sqrt{ } 2}{E_{n}-E_{f}} & {\left[1+\left(\frac{E_{n-1}-E_{f}}{E_{n}-E_{f}}\right)^{2}\right]^{\frac{1}{2}} } \\
\frac{\delta \sqrt{ } 2}{E_{\lambda}^{\prime}} & {\left[1+\left(\frac{E_{\lambda}^{\prime \prime}}{E_{\lambda}^{\prime}}\right)^{2}\right]^{\frac{1}{2}}, }
\end{aligned}
$$

if one puts $E_{n-1}-E_{f}=E_{\lambda}^{\prime \prime}$ and $E_{n}-E_{f}=E_{\lambda}^{\prime}$. The value of $\delta$ is usually \pm 0.002 .

\section{Variation in the irrelevant absorption}

Solutions of rhodopsin increase in turbidity on standing, as does aqueous digitonin itself. The value of the extinction at $700 \mathrm{~m} \mu$. should be almost entirely a measure of turbidity, as rhodopsin does not absorb appreciably in that region. It has been noticed that the value of the extinction at $700 \mathrm{~m} \mu$. decreases in some experiments during the 10 or $15 \mathrm{~min}$. required to bleach a rhodopsin solution completely. This, however, is only detectable when the turbidity is appreciable.

How, then, will these disturbances affect the 'regeneration' experiments? Presumably while the solution is frozen the 'turbidity' will be unaffected, but after thawing and during the $1 \mathrm{hr}$. wait for the solution to reach equilibrium the turbidity may change. As the cause is unknown it is not possible to allow for the effect during an experiment, but sufficiently large changes in the irrelevant absorption could alter the ratio to appreciably more or less than its true value.

\section{Absorption maximum of regenerated rhodopsin}

In a previous paper (Collins \& Morton, 1950a) it was shown that the exact position of the apparent $\lambda_{\max .}$ depends on the slope of the irrelevant absorption, but this has to be increased considerably to shift the position of $\lambda_{\max }$ by more than 2 or $3 \mathrm{~m} \mu$. Now the changes in the irrelevant absorption which may affect $r_{n}$ considerably will only have a small effect on $\lambda_{\max }$ - perhaps less than $2 \mathrm{~m} \mu$. As a result of the first regeneration the maximum of rhodopsin appears to have shifted 5-10 $\mathrm{m} \mu$. towards shorter wavelengths. Figs. 1 and 2 illustrate this. This shift always occurs, and varies but little in magnitude. It is also apparent in the difference curves.

Now, if an absorption curve is reduced in intensity (as, for example, by a lowered concentration), but is unchanged in $\lambda_{\max }$, then the ratio of the reduced absorption to the original absorption should be the same at all wavelengths. If, however, the absorption has not only been reduced but also displaced on the wavelength axis, then the ratio will vary at different wavelengths.

In Table 2 the values for $r_{n}$ at various wavelengths are shown for two experiments. Wavelengths below $420 \mathrm{~m} \mu$. are not considered here as the change on bleaching is very small. As will be seen from Table 2, $r_{1}$ varies appreciably with wavelength-it increases continuously towards shorter wavelengths-but $r_{2}$, $r_{3}$, etc., are approximately constant between 430 and $560 \mathrm{~m} \mu$. Therefore it may be concluded that after the first 'regeneration' the $\lambda_{\max }$ of rhodopsin has been

Table 2. 'Regeneration' of rhodopsin expressed as a ratio $r$ using absorptions at different wavelengths

$\left(r_{1}=E_{\lambda}^{\prime} \mid E_{\lambda}, r_{2}=E_{\lambda}^{\prime \prime} / E_{\lambda}^{\prime}\right.$, etc. The estimated experimental errors reflect the increasing importance of instrumental limita-

\begin{tabular}{|c|c|c|c|c|c|c|c|c|c|c|c|c|c|c|c|}
\hline$\lambda(\mathbf{m} \mu)$. & ... & 430 & 440 & 450 & 460 & 470 & 480 & 490 & 500 & 510 & 520 & 530 & 540 & 550 & 560 \\
\hline$\stackrel{r}{1}_{\text {Error }} \pm$ & & $\begin{array}{l}1.00 \\
0.09\end{array}$ & $\begin{array}{l}0 \cdot 78 \\
0 \cdot 04\end{array}$ & $\begin{array}{l}0.71 \\
0.03\end{array}$ & $\begin{array}{l}0 \cdot 67 \\
0.02\end{array}$ & $\begin{array}{l}0.63 \\
0 \cdot 01\end{array}$ & $\begin{array}{l}0 \cdot 61 \\
0 \cdot 01\end{array}$ & $\begin{array}{l}0.57 \\
0.01\end{array}$ & $\begin{array}{l}0.54 \\
0.01\end{array}$ & $\begin{array}{l}0.57 \\
0.01\end{array}$ & $\begin{array}{l}0.51 \\
0.01\end{array}$ & $\begin{array}{l}0.44 \\
0.01\end{array}$ & $\begin{array}{l}0.42 \\
0.02\end{array}$ & $\begin{array}{l}0.39 \\
0.02\end{array}$ & $\begin{array}{l}0.38 \\
0.03\end{array}$ \\
\hline $\begin{array}{l}r_{2} \\
\text { Error } \pm\end{array}$ & & $\begin{array}{l}0.55 \\
0.07\end{array}$ & $\begin{array}{l}0.53 \\
0.05\end{array}$ & $\begin{array}{l}0.52 \\
0.03\end{array}$ & $\begin{array}{l}0.52 \\
0.03\end{array}$ & $\begin{array}{l}0.52 \\
0.02\end{array}$ & $\begin{array}{l}0.52 \\
0.02\end{array}$ & $\begin{array}{l}0.52 \\
0.02\end{array}$ & $\begin{array}{l}0.52 \\
0.02\end{array}$ & $\begin{array}{l}0.52 \\
0.02\end{array}$ & $\begin{array}{l}0.48 \\
0.02\end{array}$ & $\begin{array}{l}0.50 \\
0.03\end{array}$ & $\begin{array}{l}0.48 \\
0.04\end{array}$ & $\begin{array}{l}0.56 \\
0.06\end{array}$ & $\begin{array}{l}0.49 \\
0.09\end{array}$ \\
\hline $\begin{array}{l}r_{3} \\
\text { Error } \pm\end{array}$ & & $\begin{array}{l}0 \cdot 38 \\
0 \cdot 13\end{array}$ & $\begin{array}{l}0 \cdot 45 \\
0 \cdot 09\end{array}$ & $\begin{array}{l}0.46 \\
0.06\end{array}$ & $\begin{array}{l}0.50 \\
0.05\end{array}$ & $\begin{array}{l}0.51 \\
0.04\end{array}$ & $\begin{array}{l}0.53 \\
0.04\end{array}$ & $\begin{array}{l}0.52 \\
0.04\end{array}$ & $\begin{array}{l}0.51 \\
0.04\end{array}$ & $\begin{array}{l}0.51 \\
0.04\end{array}$ & $\begin{array}{l}0.52 \\
0.05\end{array}$ & $\begin{array}{l}0.52 \\
0.06\end{array}$ & $\begin{array}{l}0.50 \\
0.08\end{array}$ & $\begin{array}{l}0 \cdot 39 \\
0 \cdot 10\end{array}$ & $\begin{array}{l}0.41 \\
0.18\end{array}$ \\
\hline rrror \pm & & $\begin{array}{l}1 \cdot 3 \\
0 \cdot 47\end{array}$ & $\begin{array}{l}0 \cdot 87 \\
0 \cdot 24\end{array}$ & $\begin{array}{l}0 \cdot 78 \\
0 \cdot 16\end{array}$ & $\begin{array}{l}0 \cdot 77 \\
0 \cdot 12\end{array}$ & $\begin{array}{l}0.69 \\
0 \cdot 10\end{array}$ & $\begin{array}{l}0.69 \\
0.08\end{array}$ & $\begin{array}{l}0.69 \\
0.08\end{array}$ & $\begin{array}{l}0 \cdot 69 \\
0 \cdot 08\end{array}$ & $\begin{array}{l}0.67 \\
0.09\end{array}$ & $\begin{array}{l}0 \cdot 70 \\
0 \cdot 10\end{array}$ & $\begin{array}{l}0 \cdot 70 \\
0.13\end{array}$ & $\begin{array}{l}0 \cdot 79 \\
0 \cdot 19\end{array}$ & $\begin{array}{l}0 \cdot 83 \\
0 \cdot 31\end{array}$ & $\begin{array}{l}1 \cdot 0 \\
0 \cdot 57\end{array}$ \\
\hline \multicolumn{16}{|c|}{ Rat rhodopsin } \\
\hline$r_{1}$ Error \pm & & $\begin{array}{l}0 \cdot 78 \\
0.04\end{array}$ & $\begin{array}{l}0 \cdot 67 \\
0 \cdot 03\end{array}$ & $\begin{array}{l}0 \cdot 60 \\
0.02\end{array}$ & $\begin{array}{l}0.56 \\
0.01\end{array}$ & $\begin{array}{l}0.52 \\
0.01\end{array}$ & $\begin{array}{l}0.50 \\
0.01\end{array}$ & $\begin{array}{l}0.46 \\
0.01\end{array}$ & $\begin{array}{l}0.44 \\
0.01\end{array}$ & $\begin{array}{l}0.40 \\
0.01\end{array}$ & $\begin{array}{l}0.37 \\
0.01\end{array}$ & $\begin{array}{l}0.34 \\
0.01\end{array}$ & $\begin{array}{l}0.30 \\
0.02\end{array}$ & $\begin{array}{l}0 \cdot 30 \\
0 \cdot 02\end{array}$ & $\begin{array}{l}0.27 \\
0.03\end{array}$ \\
\hline $\begin{array}{l}r_{2} \\
\text { Error } \pm\end{array}$ & & $\begin{array}{l}0.48 \\
0.04\end{array}$ & $\begin{array}{l}0.46 \\
0.03\end{array}$ & $\begin{array}{l}0.46 \\
0.02\end{array}$ & $\begin{array}{l}0.46 \\
0.02\end{array}$ & $\begin{array}{l}0.46 \\
0.02\end{array}$ & $\begin{array}{l}0.45 \\
0.02\end{array}$ & $\begin{array}{l}0 \cdot 46 \\
0 \cdot 02\end{array}$ & $\begin{array}{l}0.44 \\
0.02\end{array}$ & $\begin{array}{l}0.45 \\
0.02\end{array}$ & $\begin{array}{l}0.45 \\
0.03\end{array}$ & $\begin{array}{l}0.43 \\
0 \cdot 04\end{array}$ & $\begin{array}{l}0.41 \\
0.05\end{array}$ & $\begin{array}{l}0 \cdot 37 \\
0.08\end{array}$ & $\begin{array}{l}0 \cdot 46 \\
0 \cdot 14\end{array}$ \\
\hline $\begin{array}{l}r_{3} \\
\text { Error } \pm\end{array}$ & & $\begin{array}{l}0.46 \\
0.90\end{array}$ & $\begin{array}{l}0 \cdot 49 \\
0 \cdot 08\end{array}$ & $\begin{array}{l}0.46 \\
0.06\end{array}$ & $\begin{array}{l}0.45 \\
0.05\end{array}$ & $\begin{array}{l}0.42 \\
0.05\end{array}$ & $\begin{array}{l}0.45 \\
0.04\end{array}$ & $\begin{array}{l}0.42 \\
0.04\end{array}$ & $\begin{array}{l}0.46 \\
0.05\end{array}$ & $\begin{array}{l}0.41 \\
0.05\end{array}$ & $\begin{array}{l}0.41 \\
0.06\end{array}$ & $\begin{array}{l}0.42 \\
0.08\end{array}$ & $\begin{array}{l}0 \cdot 35 \\
0 \cdot 13\end{array}$ & $\begin{array}{l}0.43 \\
0.22\end{array}$ & $\begin{array}{l}0.50 \\
0.32\end{array}$ \\
\hline$\stackrel{r}{4}_{\text {Error }} \pm$ & & $\begin{array}{l}0 \cdot 44 \\
0 \cdot 20\end{array}$ & $\begin{array}{l}0.50 \\
0 \cdot 16\end{array}$ & $\begin{array}{l}0.48 \\
0.14\end{array}$ & $\begin{array}{l}0 \cdot 46 \\
0 \cdot 12\end{array}$ & $\begin{array}{l}0 \cdot 48 \\
0 \cdot 12\end{array}$ & $\begin{array}{l}0 \cdot 48 \\
0 \cdot 10\end{array}$ & $\begin{array}{l}0.53 \\
0.11\end{array}$ & $\begin{array}{l}0.50 \\
0 \cdot 11\end{array}$ & $\begin{array}{l}0.50 \\
0 \cdot 13\end{array}$ & $\begin{array}{l}0 \cdot 50 \\
0 \cdot 16\end{array}$ & $\begin{array}{l}0 \cdot 60 \\
0 \cdot 17\end{array}$ & $\begin{array}{l}0.50 \\
0 \cdot 40\end{array}$ & $\begin{array}{l}0 \cdot 67 \\
0 \cdot 57\end{array}$ & $\begin{array}{l}0 \cdot 20 \\
0.58\end{array}$ \\
\hline
\end{tabular}
tions as $E$ values decrease. Error $=\frac{ \pm \delta \sqrt{ } 2}{E_{\lambda}}\left[1+\left(\frac{E_{\lambda}^{\prime}}{E_{\lambda}}\right)^{2}\right]^{z}$, where $\delta=0.002$ and is the error in reading the extinction.) 
shifted, but that subsequent 'regenerations' have no further effect on its position. Because of these differences it is proposed to call the 'regenerated' material isorhodopsin.

\section{Is the rhodopsin absorption halved?}

Table 2 also shows that $r_{2}, r_{3}$ and $r_{4}$ are approximately constant and are not greatly different from 0.5 . Fig. 1 shows the experiment in which the purest solution of rhodopsin yet obtained was used (Collins \& Morton, $1950 a$ ). Even with this pure solution the increase in turbidity was large, but in the region $>430 \mathrm{~m} \mu$. it was less than in any other experiment and $r_{2}$ and $r_{3}$ cannot be far from the true value. It if the rhodopsin and isorhodopsin curves are similar in shape, but differ only in $\lambda_{\max }$, the difference between their crossover points with indicator yellow must be less than the interval between their respective maxima. In fact the observed difference is about the same, and this must be due either to the changes in the irrelevant absorption or to differences in the shape of therhodopsin and $i s o r h o d o p s i n$ curves.

If the absorption at any wavelength is expressed as a fraction of that at $\lambda_{\max }$ we obtain the results, set out in Table 3, using the data of Table 1 for the difference spectra of ox rhodopsin. These results show that the two curves have exactly the same shape.*

Table 3. Absorption of rhodopsin and isorhodopsin expressed as a fraction of the maximum absorption ( $\lambda_{\text {max. }}$ for rhodopsin $500 \mathrm{~m} \mu$., for isorhodopsin $492 \mathrm{~m} \mu$.)

$\begin{array}{lccccccccccccc}\lambda_{\max .}-\lambda_{(\mathbf{m} \mu .)} & -60 & -50 & -40 & -30 & -20 & -10 & 0 & 10 & 20 & 30 & 40 & 50 & 60 \\ \text { Rhodopsin } & 0.39 & 0.49 & 0.63 & 0.77 & 0.88 & 0.96 & 1.00 & 0.96 & 0.88 & 0.74 & 0.57 & 0.40 & 0.26 \\ \text { isoRhodopsin } & 0.29 & 0.46 & 0.61 & 0.76 & 0.88 & 0.97 & 1.00 & 0.97 & 0.89 & 0.75 & 0.59 & 0.41 & 0.28\end{array}$

should be noted that the fifth curve (Fig. 1) is slightly anomalous; this is supported by the fact that the irrelevant absorption at $700 \mathrm{~m} \mu$. was 0.010 as compared to 0.007 for the curves before and after it.

A precise value for $r_{n}$ could be obtained with pure stable rhodopsin solutions, but it is already clear that $r_{n}(n>1)$ is not far from 0.5 , and that divergences from 0.5 are consistent with changes in the irrelevant absorption.

It is evident from Fig. 1 that the indicator yellow absorption increases pari passu with the decrease in that of rhodopsin and isorhodopsin, but a strictly quantitative treatment of the problem must be deferred at this stage.

\section{Is there an isosbestic point?}

If it is true that there are two forms of rhodopsin and only one form of indicator yellow (provided the $\mathrm{pH}$ is constant), then after the first regeneration the remaining curves should all pass through an isosbestic point where the molecular extinction co-
Towards shorter wavelengths we should expect the small differences shown, because the indicator yellow is unaltered and so should affect the two difference curves slightly differently. The close correspondence shown above supports the first alternative, that the irrelevant absorption has changed enough slightly to displace the isosbestic point from its expected position.

\section{Conclusions}

It is proposed to consider three working hypotheses which together fit the observed facts. It is recognized that alternatives may be possible for any one or all of these hypotheses. Although they are immediately serviceable, only future experimentation can decide their validity or otherwise.

Hypothesis (1). The conversion of rhodopsin to indicator yellow is an oxidative process involving the loss of two electrons.

Hypothesis (2). The following structure for the rhodopsin chromophoric group is proposed.

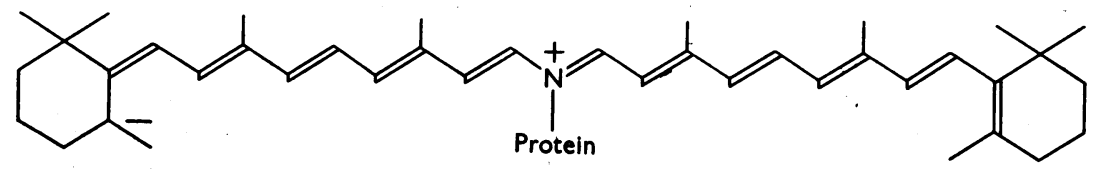

(and at least eleven other resonance forms, those with the negative charge on the carbon atoms adjacent to the nitrogen atom being the most probable).

efficient of the indicator yellow is equal to that of the isorhodopsin. However, if the irrelevant absorption should change, an isosbestic point may not be apparent or may be displaced.

In Fig. 1, for example, there appears to be an isosbestic point at about $415 \mathrm{~m} \mu$. which the unbleached curve does not pass through. However, it can be shown by considering the slopes of the curves that,
This hypothesis depends partly on hypothesis (1) and partly on the structure proposed previously (Collins \& Morton, 1950b) for indicator yellow.

Hypothesis (3). The absorption spectrum of isorhodopsin is due to a single rhodopsin chromophoric group on the protein, while that of rhodopsin is due

\footnotetext{
* $\lambda_{\max .}$ rhodopsin, $500 \mathrm{~m} \mu . \lambda_{\max .}$ isorhodopsin, $492 \mathrm{~m} \mu$.
} 
to two chromophoric groups adjacently situated on the same protein molecule and interacting to some extent. This hypothesis is independent of the other two.

It is now proposed to examine the experimental results in relation to these hypotheses. The decomposition of rhodopsin can be written as follows:

Rhodopsin $+n \boldsymbol{h} \nu \rightarrow$ transient orange.

Two transient orange $\rightarrow$ indicator yellow + isorhodopsin.

isoRhodopsin $+n \boldsymbol{h} v \rightarrow$ transient orange.

Two transient orange $\rightarrow$ etc.

Freezing to $-70^{\circ}$ stops the reaction at the transient orange stage, while warming to room temperature isolates the thermal reaction. The simplest explanation of this reaction is that transient orange is a free radical, and dismutates as shown above. This irnplies that rhodopsin loses an electron as follows:

$$
\text { Rhodopsin }+n \boldsymbol{h} \nu \rightarrow \text { transient orange }+e^{-} \text {. }
$$

Accordingly, the chromophoric group of transient orange can be written:<smiles>C=CC(C)=CC=CC(C)=CC=C1C(C)CCCC1(C)C</smiles>

Dismutation will result in half the transient orange chromophoric groups losing another electron and forming indicator yellow :<smiles>C/C=C/C(C)=C/C=C/C(C)=C/C=C1C(C)=CCCC1(C)C</smiles>

This series of reactions accounts for the apparent regeneration reported earlier in this paper.

In a previous paper (Collins \& Morton, 1950b) it was shown that the molecular extinction coefficient for rhodopsin was about 48,000p where the concentration was $6.06 \times 10^{23}$ chromophoric groups per litre and where $p$ was equal to the number of vitamin A (or retinene) residues per chromophoric group. According to hypothesis (2), $p$ will be equal to 2 and hence $\epsilon_{\max }=$ approx. 96,000.

Schneider, Goodeve \& Lythgoe (1939) showed that $\epsilon_{\max _{0} \cdot \gamma}$ (=quantum efficiency)=approx. 24,000, and hence $\gamma$ will be about 0.25 (the overall quantum efficiency). As the dismutation of transient orange reduces the quantum yield by one-half, the quantum efficiency of the primary reaction must be about $0 \cdot 5$. The exact mechanism and energy relationships involved must be left for future work to elucidate, but it is unlikely that one chromophoric group absorbs two quanta. It is more likely that there is either an internal deactivation, or a transference of energy between two activated rhodopsin chromophoric groups.
If the value of $\epsilon_{\max }$ for rhodopsin is aloout 96,000, and if the results of Broda, Goodeve \& Lythgoe (1940) for a minimum value for $E_{1 \mathrm{~cm}}^{1 \%}$ $(500 \mathrm{~m} \mu)=.6 \cdot 6$ are accepted, then it follows that the maximum value for the carrier weight is 145,000 . The value for the molecular weight is 270,000 (Hecht \& Pickels, 1938), and hence there must be two chromophoric groups per molecule.

If these results are compared with the calculations of Collins \& Morton (1949) two further results can be deduced. It was shown that $\epsilon_{\max }=65,000 \mathrm{f}$, where $f^{*}$ is the oscillator strength of the absorption band $\left(\lambda_{\max }=500 \mathrm{~m} \mu\right.$. $)$ of rhodopsin. Hence, if $\epsilon_{\max }=96,000, f$ will $=1 \cdot 48$. It also follows, assuming the molecular weight of 270,000 is correct (and this needs to be confirmed with pure rhodopsin), that $E_{1}^{1 \%}$. will $=7 \cdot 1$. This value is quite close to that found by Broda et al. (1940).

Ordinary rhodopsin is therefore assumed to consist of two chromophoric groups attached to the same protein molecule and manifesting some mutual interaction, thus shifting the $\lambda_{\max }$. slightly towards<smiles>CC1=C(/C=C/C(C)=C/C=C/C(C)=C/C=[N+](/C)C(=O)OCc2ccccc2)C(C)(C)CCC1</smiles>

longer wavelength. As the result of the absorption of light and the subsequent intramolecular dismutation of transient orange, one chromophoric<smiles>C/C=C(C)/C=C/C=C(C)/C=C/C1=C(C)CC[C@H](P)C1(C)C</smiles>

group will have been converted to indicator yellow leaving only one chromophoric group per molecule. This is isorhodopsin, and it will have its $\lambda_{\max }$ at a wavelength characteristic of the isolated chromophoric group. Subsequent dismutation of any transient orange will be intermolecular and will result in the continued formation of isorhodopsin.

Although there are still many gaps in our knowledge of rhodopsin, it is believed that the present theory consolidates the known facts and will act as a guide to future research even if it does not turn out to be correct in all particulars.

\section{SUMMARY}

1. If rhodopsin is irradiated at $-70^{\circ}$ and then allowed to reach equilibrium in the dark at room temperature two phenomena are apparent : $(a)$ there

* The oscillator strength is defined as follows:

$$
f=4 \cdot 31 \times 10^{-9} \int \epsilon d v \text {, }
$$

where $\epsilon=$ molecular extinction coefficient, and $v=$ wave number in $\mathrm{cm} .^{-1}$. The limits of the integration are to include an absorption band due to one electronic transition (cf. Collins \& Morton, 1949). 
is apparently $50 \%$ regeneration; (b) $\lambda_{\max }$ is shifted about $8 \mathrm{~m} \mu$. towards shorter wavelengths.

2. This result has been obtained with frog, rat and ox rhodopsin, and the amount of regeneration is, within the experimental error, $50 \%$.

3. A working hypothesis concerning the structure of the rhodopsin chromophore and the mechanism of its photodecomposition is presented.

One of us (F.D.C.) participated in this work as a holder of a New Zealand National Research Scholarship. We are indebted to the Medical Research Council and the Ministry of Food for a grant.

\title{
REFERENCES
}

Broda, E. E. \& Goodeve, C. F. (1941). Proc. roy. Soc. B, 130, 217.

Broda, E. E., Goodeve, C. F. \& Lythgoe, R. J. (1940). J. Physiol. 98, 397.

Chase, A. M. \& Smith, E. L. (1939). J. gen. Physiol. 23, 21.

Clark, W. M. (1928). The Determination of Hydrogen Ions, 3rd ed. London: Baillière, Tindall and Cox.

Collins, F. D. \& Morton, R. A. (1949). Nature, Lond., 164, 528.
Collins, F. D. \& Morton, R. A. (1950a). Biochem. J. 47. 3. Collins, F. D. \& Morton, R. A. (1950b). Biochem. J. 47, 10.

Hecht, S. \& Pickels, E. G. (1938). Proc. nat. Acad. Sci., Wash., 24, 172.

Lythgoe, R. J. (1940). Brit. J. Ophthal. 24, 21.

Lythgoe, R. J. \& Quilliam, J. P. (1938). J. Physiol. 94, 399.

Schneider, E. E., Goodeve, C. F. \& Lythgoe, R. J. (1939). Proc. roy. Soc. A, 170, 102.

\section{Effect of Sulphonamides on the Aneurin Economy in Animals}

\author{
By C. C. KRATZING* aNd E. C. SLATER, $\dagger$ \\ Australian Institute of Anatomy, Commonwealth Department of Health, Canberra, Australia
}

(Received 6 December 1949)

It is well established that many of the toxic effects of sulphonamides on animals fed purified diets are caused by inhibition of bacterial synthesis of some of the $B$ vitamins in the intestine, resulting in a definite syndrome due to the deficiency of these vitamins. Few attempts have been made, however, to determine if the sulphonamides have a more direct effect on the metabolism of the $B$ vitamins in the animal body. In a preliminary report (Slater, 1946), it was shown that sulphadiazine caused an alteration of the aneurin economy in the animal (human and rat), and that this effect was apparently unrelated to bacterial synthesis. Further studies of this effect have now been made, with the primary object of determining whether it possessed any similarity to the action of sulphonamides on micro-organisms, e.g. whether it was reversed by $p$-aminobenzoic acid (PAB).

\section{METHODS}

Animals and cages. Hooded rats of an inbred strain were used. They were weaned at 3 weeks and were usually 4-5 weeks old at the start of the experiment. Different groups were carefully matched with regard to litter, sex and body

* Present address, Research Laboratory, Maudsley Hospital, London, S.E. 5.

$\dagger$ Present address, Molteno Institute, University of Cambridge. weight. The rats were housed in individual cages with wiremesh floors. The food consumption was measured to the nearest $0.05 \mathrm{~g}$. Water was provided ad lib.

Diets. One of the aims of this investigation was to determine if the effect of sulphonamides on animal tissues was reversed by PAB. It was necessary, therefore, to use a diet which did not contain any $\mathrm{PAB}$. At the time when this work was started (1944-5), it was impossible to obtain sufficient pure folic acid and biotin to prepare a purified diet, essentially free from PAB, containing these two vitamins. Thus the basal diet used in the early experiments was deficient, not only in PAB, but also in folic acid and biotin. Rats fed such a diet without any sulphonamide do not develop biotin or folic acid deficiency, since the two vitamins are normally provided in adequate amounts by bacterial synthesis in the intestine. The addition of sulphonamides to the diet, however, prevents the growth of the bacteria responsible for this synthesis and, consequently, precipitates a folic acid and biotin deficiency. Later, when it was shown that PAB did not reverse the effect of sulphadiazine, it was possible to use a basal diet containing both PAB and sufficient dried liver to supply all the folic acid and probably the biotin required by the rat. It was found that $4 \%$ dried ox-liver powder in the diet was sufficient to prevent the blood dyscrasia which occurred when sulphonamides were incorporated in the diet lacking the liver powder. Thus two different diets, $A$ (deficient in folic acid, biotin and $\mathrm{PAB}$ ) and $B$ (containing these vitamins) were employed in these experiments. The vitamins whose metabolism was being studied were fed daily to each rat by pipette. The other vitamins were incorporated in the food. The composition of the two diets is given in Table 1 . 